\title{
Disorders of Sexual Development in Proximal Hypospadias in Children
}

Amin M. Abokifa, Refaat I. El Badawy, Hesham W. Anwar, Yahia E. EI Sagheer

Department of General Surgery, Faculty of Medicine, Al-Azhar University

\begin{abstract}
Background: Hypospadias is seen in around one in 300 live births, making it the most prevalent congenital penile abnormality. Objective: to evaluate of the incidence and diagnosis of disorders of sexual development in proximal hypospadias. Patients and Methods: This prospective study was conducted on 44 children attending the Pediatric Surgery Department, Al-Azhar University Hospitals during the period from Dec 2018 to Nov 2019. Detailed history taking; including complete physical examination, examination with special focus on external genitalia and gonads; routine and specific laboratory investigation as genetic karyotyping, serum testosterone (T), dihydrotestosterone, dehydroandrostenedione, $17 \mathrm{OH}$ progesterone, HCG stimulation test, serum levels of luteinizing hormone (LH) and follicle-stimulating hormone (FSH), Adrenal hormones "serum cortisol \& plasma adrenocorticotropic hormone $(\mathrm{ACTH})$ "to exclude congenital adrenal hyperplasia. Ultrasound abdomen and pelvis was routinely done to assess the internal genital organs " uterus, fallopian tubes " and gonads " testis, ovaries ". Results: there are (5) patients diagnosed as DSD: Three cases $(6.8 \%)$ have Karyotyping (46, XX), diagnosed as CAH. One case (2.2\%) has Karyotyping (46XY (70\%)/45X (30) sex chromosome DSD (45, X/46, XY PGD) or "mixed gonadal dysgenesis". One case (2.2\%) has Karyotyping (46, xy), diagnosed as complete Androgen insensitivity syndrome. Conclusion: Patients presenting with proximal hypospadias and one or more of the co-existing anomalies of micro penis, undescended/impalpable testes, and penoscrotal transposition/bifid scrotum should warrant DSD evaluation. Presence of bilaterally descended testes in scrotum does not preclude the possibility of DSD.
\end{abstract}

Keywords: DSD, Proximal Hypospadias, Children.

\section{INTRODUCTION}

Hypospadias is a common penile anomaly occurring in 1 of 200 to 300 live births. Most cases encountered in clinical practice are distal hypospadias while minorities of patients have proximal hypospadias (1). Most cases of hypospadias are considered as an isolated anatomical defect. In a small group of patients, however, hypospadias may be a part of the presentation of a more complex anomaly of a disorders of sex development (DSD) ${ }^{(2)}$.

The birth of a child with ambiguous external genitalia is highly distressing to families. The first question parents ask about their newborn is whether it is a boy or a girl. The birth of a newborn with ambiguous genitalia comes as a surprise for the parents and doctors alike ${ }^{(3)}$.

DSD are defined as congenital conditions associated with atypical development of chromosomal, gonadal, or anatomical sex ${ }^{(4)}$.

DSD is associated with micro penis, scrotal anomaly and undescended/ impalpable testis. A previous study reported that chromosomal abnormalities were noted in $32 \%$ of patients with proximal hypospadias and undescended testis, in contrast to zero among those with distal hypospadias and undescended testis ${ }^{(\mathbf{5}}$.

Experts opinions recommended that hypospadias associated with undescended testis or bifid scrotum should be evaluated for DSD ${ }^{(6)}$.

The most consistent investigations are karyotype analysis, serum levels of testosterone (T) and Dihydrotestosterone (DHT) at baseline or following HCG stimulation test, serum levels of luteinizing hormone and follicle-stimulating hormone. If DSD was diagnosed, affected patients had 46, XX DSD, or 46, XY DSD, or Sex Chromosome DSD ${ }^{(4)}$.

\section{AIM OF THE STUDY}

The aim of this study was to evaluate the incidence and diagnosis of disorders of sexual development in proximal hypospadias in children.

\section{PATIENTS AND METHODS}

This is a prospective single arm clinical trial for evaluation of the incidence and diagnosis of disorders of sexual development in proximal hypospadias in 44 Child attending the Pediatric Surgery Department, AlAzhar University Hospitals. The duration of the study is one years (Dec 2018- Nov 2019).

The study included all patients with proximal hypospadias, with or without micro penis, undescended testes, scrotal transposition and bifid scrotum aged 1 day till 14 years. While patients with ages more than 14 years or suffering from distal hypospadias were excluded from the study.

All patients included in this study were subjected to history taking including personal patients including age and sex of rearing. In addition, parents were also inquired about consanguinity and a family history of similar conditions or other types of DSD.

The patient's mothers were asked for previous intake of hormonal therapy shortly before or during pregnancy. They were also inquired about any manifestations of hormone secreting tumors or surgery for excision of such tumors. 


\section{Ethical approval:}

The study was approved by the medical ethics committee of Al-Azhar University Hospitals and a written informed consent is obtained from all patients.

\section{Physical Examination}

General examination of chest and abdomen as well as genitourinary system. Local physical examination was done carefully and meticulously. External genitalia were:

1. Inspected for phallus size, site of meatal orifice, scrotal shape and development.

I. Male patients were classified according to External Masculinization Score.

Calculating the External Masculinization Score provides an objective aggregate score of the extent of masculinization of the external genitalia. Each individual feature of the genitalia (phallus size, labioscrotal fusion, site of the gonads and location of urethral meatus) can be individually scored to provide a score out of $12^{(7)}$.

II. Female patients were classified according to Prader's classification from 1 to 5: 1 . Female external genitalia with clitoromegaly. 2. Clitoromegaly with partial labial fusion forming a funnel-shaped urogenital sinus. 3. Increased phallic size with complete labioscrotal fusion forming a urogenital sinus with a single opening. 4. Complete scrotal fusion with the opening of the urogenital sinus at the base of the phallus. 5. Normal male external genitalia.

\section{Investigations}

\section{Lab investigations:}

(A) Routine Labs: Complete blood picture, urine analysis, blood urea, serum creatinine, liver function tests, coagulation profile and serum electrolytes ( $\mathrm{Na}$ and K). (B) Specific Labs: Genetic karyotyping was done for all patients in this study, serum testosterone (T), dihydrotestosterone, dehydro-androstenedione, $17 \mathrm{OH}$ progesterone, HCG stimulation test, serum levels of luteinizing hormone (LH) and follicle-stimulating hormone (FSH). Adrenal hormones serum cortisol \& plasma adrenocorticotropic Hormone (ACTH) to exclude Congenital Adrenal hyperplasia.

\section{Imaging Studies:}

Ultrasound abdomen and pelvis was routinely done to assess the internal genital organs "uterus, fallopian tubes" and gonads " testis, ovaries". Specific Studies: Gonadal biopsy for some patients using diagnostic laparoscope. Each case was managed accordingly and the results were recorded.

\section{Statistical analysis}

Recorded data were analyzed using the statistical package for social sciences, version 20.0 (SPSS Inc., Chicago, Illinois, USA). Quantitative data were expressed as mean \pm standard deviation (SD).
Qualitative data were expressed as frequency and percentage.

The following tests were done: Independentsamples t-test of significance was used when comparing between two means. Chi-square $\left(\mathrm{x}^{2}\right)$ test of significance was used in order to compare proportions between qualitative parameters. The confidence interval was set to $95 \%$ and the margin of error accepted was set to $5 \%$. So, the p-value was considered significant as the following: Probability (P-value); P-value $<0.05$ was considered significant. $\mathrm{P}$-value $<0.001$ was considered as highly significant. $\mathrm{P}$-value $>0.05$ was considered insignificant.

\section{RESULTS}

\section{Examination:}

Table (1): Phallus size, site of the meatus and shape of the L/S distribution of the study group.

\begin{tabular}{|l|c|}
\hline & Total (n=44) \\
\hline Phallus size (micropenis or not) & $3(6.8 \%)$ \\
\hline Clitoromegaly & $7(15.9 \%)$ \\
\hline Yes (microphallus) & $34(77.3 \%)$ \\
\hline No & $3(6.8 \%)$ \\
\hline Site of the meatus & $15(34.1 \%)$ \\
\hline At the base of phallus & $11(25.0 \%)$ \\
\hline Post Penile & $13(29.5 \%)$ \\
\hline Peno scrotal & $2(4.5 \%)$ \\
\hline Scrotal & $16(36.4 \%)$ \\
\hline Perineal & $28(63.6 \%)$ \\
\hline Shape of the L/S (labioscrotal) \\
\hline Bifid & Clitoromegaly 3 \\
\hline Fused & This table shows that the \\
(6.8\%), No 34 (77.3\%), and Yes 7 (15.9\%) of
\end{tabular}

Microphallus; Post Penile 15 (34.1\%), Peno scrotal 11 (25.0\%), Scrotal 7 (15.9\%), Scrotal hyposp. 6 (13.6\%), At the base of phallus $3(6.8 \%)$ and Perineal $2(4.5 \%)$ of Site of the meatus; while Bifid 16 (36.4\%) and Fused $28(63.6 \%)$ of Shape of the $\mathbf{L} / \mathbf{S}$

Table (2): Palpation of gonads:

\begin{tabular}{|l|c|}
\hline Gonade & Total $(\mathbf{n}=\mathbf{4 4})$ \\
\hline Right & $1(2.3 \%)$ \\
\hline Absent & $3(6.8 \%)$ \\
\hline Inguinal & \\
\hline Left & $1(2.3 \%)$ \\
\hline Absent & $1(2.3 \%)$ \\
\hline Inguinal & $2(4.5 \%)$ \\
\hline Scrotal & \\
\hline Bilateral & $4(9.1 \%)$ \\
\hline Absent & $9(20.5 \%)$ \\
\hline Inguinal & $27(61.4 \%)$ \\
\hline Scrotal & \\
\hline
\end{tabular}

This table shows that the Right Absent 1 (2.3\%) and Inguinal 3 (6.8\%); Left Absent 1 (2.3\%), Inguinal $1(2.3 \%)$ and Scrotal 2 (4.5\%); while 
Bilateral Absent 4 (9.1\%), Inguinal 9 (20.5\%) and Scrotal 27 (61.4\%).

Table (3): Comparison between DSD and proximal hypospadias according to gonad.

\begin{tabular}{|c|c|c|c|c|c|c|}
\hline \multirow[t]{2}{*}{ Gonad } & \multicolumn{2}{|c|}{$\begin{array}{c}\text { DSD } \\
(n=5)\end{array}$} & \multicolumn{2}{|c|}{$\begin{array}{l}\text { Proximal } \\
\text { Hypospadi } \\
\text { as }(n=39)\end{array}$} & \multirow[t]{2}{*}{ x2\# } & \multirow{2}{*}{$\begin{array}{c}\text { p- } \\
\text { value }\end{array}$} \\
\hline & $\begin{array}{l}\text { N } \\
\text { o. }\end{array}$ & $\%$ & $\begin{array}{l}\text { N } \\
\text { o. }\end{array}$ & $\%$ & & \\
\hline \multicolumn{7}{|l|}{ Right } \\
\hline Absent & 1 & $20.0 \%$ & 0 & $0.0 \%$ & \multirow[b]{2}{*}{8.258} & \multirow[b]{2}{*}{$0.016^{*}$} \\
\hline $\begin{array}{l}\text { Inguin } \\
\text { al }\end{array}$ & 0 & $0.0 \%$ & 3 & $7.7 \%$ & & \\
\hline \multicolumn{7}{|l|}{ Left } \\
\hline Absent & 0 & $0.0 \%$ & 1 & $2.6 \%$ & \multirow{3}{*}{8.258} & \multirow{3}{*}{$0.041 *$} \\
\hline $\begin{array}{l}\text { Inguin } \\
\text { al }\end{array}$ & 1 & $20.0 \%$ & 0 & $0.0 \%$ & & \\
\hline Scrotal & 0 & $0.0 \%$ & 2 & $5.1 \%$ & & \\
\hline \multicolumn{7}{|l|}{$\begin{array}{l}\text { Bilater } \\
\text { al }\end{array}$} \\
\hline Absent & 3 & $60.0 \%$ & 1 & $2.6 \%$ & 11.37 & $0.007 *$ \\
\hline $\begin{array}{l}\text { Inguin } \\
\text { al }\end{array}$ & 1 & $20.0 \%$ & 8 & $20.5 \%$ & 0.317 & 0.574 \\
\hline Scrotal & 0 & $0.0 \%$ & 27 & $69.2 \%$ & 6.269 & $0.012 *$ \\
\hline
\end{tabular}

This table shows statistically significant difference between DSD and proximal hypospadias according to gonad.

Table (4): Development of the scrotum:

\begin{tabular}{|l|l|}
\hline Development of the scrotum & Total $(\mathbf{n}=\mathbf{4 1})$ \\
\hline Under Development & $7(17.1 \%)$ \\
\hline Well Development & $34(82.9 \%)$ \\
\hline
\end{tabular}

This table shows that the underdevelopment (17.1\%) and well development $(82.9 \%)$ of development of the scrotum.

Table (5): Comparison between DSD and proximal hypospadias according to Development of the scrotum.

\begin{tabular}{|l|c|c|c|c|c|c|}
\hline & \multicolumn{2}{|c|}{$\begin{array}{c}\text { DSD } \\
(\boldsymbol{n}=5)\end{array}$} & \multicolumn{2}{c|}{$\begin{array}{c}\text { Proximal } \\
\text { Hypospadi } \\
\text { as (n=39) }\end{array}$} & \multirow{2}{*}{ x2 } & \multicolumn{1}{c|}{$\begin{array}{c}\text { p- } \\
\text { value }\end{array}$} \\
\cline { 2 - 6 } & No. & \% & No. & \% & & \\
\hline $\begin{array}{l}\text { Development } \\
\text { of the scrotum }\end{array}$ & & & & & & \\
\hline $\begin{array}{l}\text { Under } \\
\text { Development }\end{array}$ & 2 & $40.0 \%$ & 4 & $10.3 \%$ & 0.063 & 0.802 \\
\hline $\begin{array}{l}\text { Well } \\
\text { Development }\end{array}$ & 0 & $0.0 \%$ & 35 & $89.7 \%$ & 8.522 & $0.004 *$ \\
\hline
\end{tabular}

This table shows statistically significant difference between DSD and proximal hypospadias according to development of the scrotum.
Table (6): Genetic Karyotyping:

\begin{tabular}{|l|l|}
\hline Karyotyping & Total $(\mathbf{n}=\mathbf{4 4})$ \\
\hline $46 \mathrm{XX}$ & $3(6.8 \%)$ \\
\hline $46 \mathrm{XY}$ & $40(90.9 \%)$ \\
\hline 46XY $(70 \%) / 45 X(30 \%)$ & $1(2.3 \%)$ \\
\hline \multicolumn{2}{|c|}{ This table shows that the patients with 46xx } \\
$(6.8 \%), 46 x y(90.9 \%)$ and $(46 \mathrm{XY} 70 \%) /(45 \mathrm{X} 30 \%)$ of \\
$(2.3 \%)$ in karyotyping.
\end{tabular}

Table (7): Mulleriun duct remnant by US or diagnostic lab.:

\begin{tabular}{|l|l|}
\hline $\begin{array}{l}\text { Mulleriun duct remnant by } \\
\text { US or diagnostic lab. }\end{array}$ & Total $(\mathbf{n = 4 4 )}$ \\
\hline Ultrasonographic & \\
\hline Absent & $40(90.0 \%)$ \\
\hline Present & $3(6.8 \%)$ \\
\hline Laparoscopic Finding & \\
\hline Present & $1(2.3 \%)$ \\
\hline
\end{tabular}

This table shows that the absent $(90.0 \%)$ and present $(6.8 \%)$ of ultrasonographic, while present $(2.3 \%)$ of laparoscopic finding.

Table (8): Comparison between DSD and proximal hypospadias according to Mulleriun duct remnant by US or diagnostic lab.

\begin{tabular}{|c|c|c|c|c|c|c|}
\hline \multirow{2}{*}{$\begin{array}{l}\text { Mulleriun } \\
\text { duct } \\
\text { remnant } \\
\text { by US } \\
\text { or } \\
\text { diagnostic } \\
\text { lab. }\end{array}$} & \multicolumn{2}{|c|}{$\begin{array}{l}\text { DSD } \\
(n=5)\end{array}$} & \multicolumn{2}{|c|}{$\begin{array}{l}\text { Proximal } \\
\text { Hypospad } \\
\text { ias }(n=39)\end{array}$} & \multirow{2}{*}{$\mathbf{x} 2$} & \multirow{2}{*}{$\begin{array}{c}\text { p- } \\
\text { value }\end{array}$} \\
\hline & No. & $\%$ & No. & $\%$ & & \\
\hline $\begin{array}{l}\text { Ultra- } \\
\text { sonographic }\end{array}$ & & & & & & \\
\hline Absent & 1 & $\begin{array}{c}20.0 \\
\%\end{array}$ & 39 & $\begin{array}{c}100.0 \\
\%\end{array}$ & \multirow{4}{*}{25.112} & \multirow{4}{*}{$\begin{array}{c}<0.001 \\
* *\end{array}$} \\
\hline Present & 3 & $\begin{array}{c}60.0 \\
\% \\
\end{array}$ & 0 & $0.0 \%$ & & \\
\hline $\begin{array}{l}\text { Laparoscopic } \\
\text { Finding } \\
\end{array}$ & & & & & & \\
\hline Present & 1 & $\begin{array}{c}20.0 \\
\%\end{array}$ & 0 & $0.0 \%$ & & \\
\hline
\end{tabular}

This table shows statistically significant difference between DSD and proximal hypospadias according to ultrasonographic and laparoscopic finding.

Table (9): DSD distribution of the study group.

\begin{tabular}{|l|l|}
\hline DSD & Total $(\mathbf{n}=\mathbf{4 4})$ \\
\hline DSD & $5(11.4 \%)$ \\
\hline Proximal Hypospadias & $39(88.6 \%)$ \\
\hline
\end{tabular}

This table shows that the DSD (11.4\%) and proximal hypospadias $(88.6 \%)$.

In this study we found that there are (5) patients diagnosed as DSD:

- Three cases $(6.8 \%)$ have Karyotyping $(\mathbf{4 6}, \mathbf{X X})$, grade 4 of Prader's score and hormonal profile show 
High level of $17 \mathrm{OH}$ progesterone and High level of testosterone, Diagnosed as CAH.

- One case has Karyotyping (2.2\%) (46XY (70\%)/45X(30)) Sex Chromosome DSD $(45, \mathrm{X} / 46, \mathrm{XY}$ PGD) Or "Mixed Gonadal Dysgenesis"

- One case (2.2\%) has Karyotyping (46,xy), Female phenotype presented with Bil. inguinal hernia with palpable gonads, histopathology of gonadal biopsy revealed testicular tissue, diagnostic laparoscopy which revealed no mullerian duct remnant, vas and vessels entering the ring, Hormonal profile show elevated L.H. diagnosed as Complete Androgen Insensitivity Syndrome.

\section{DISCUSSION}

Diagnosis of DSD in hypospadias patients is not for academic interest but clinically relevant in gonadal management, genetic counselling, predicting fertility potential and long-term outcomes ${ }^{(8)}$.

Hypospadias associated with undescended testis or bifid scrotum should be evaluated for DSD. Micro penis and incomplete scrotal fusion are both features reflecting under virilization of male external genitalia. Penoscrotal transposition and/or bifid scrotum are clinical presentations of incomplete scrotal fusion. We suggest that boys presenting with proximal hypospadias together with one or more of the co-existing anomalies including micro penis, penoscrotal transposition/bifid scrotum, and undescended/impalpable testis should warrant evaluation for DSD. Others have advocated a stricter approach which investigates all proximal hypospadias, or any type of hypospadias associated with micro penis or undescended testes. ${ }^{(8)}$.

- In Wong et al. ${ }^{(8)}$ study, $8.5 \%$ of proximal hypospadias patients had a specific diagnosis of DSD.

- Other studies of DSD in hypospadias focused on incidence rates of abnormal chromosome ${ }^{(5)}$.

- In the current study, $11.4 \%$ of proximal hypospadias patients had a specific diagnosis of DSD.

In Wong et al. ${ }^{(8)}$ study, there are 165 patients who were eligible for this study. 58/165(35\%) patients had been evaluated for DSD. 14/165(8.5\%) patients had specific diagnoses of DSD, which included 46, XY DSD $(n=7), 46, X X$ testicular $\operatorname{DSD}(n=1)$ and Sex Chromosome $\operatorname{DSD}(\mathrm{n}=6)$.

In the current study, there are (5/44) $(11.4 \%)$ patients of proximal Hypospadias diagnosed as DSD:

- Three cases (6.8\%) have Karyotyping (46, XX), Diagnosed as CAH.

- One case (2.2\%) has Karyotyping (46XY (70\%)/ 45 X (30)) Sex Chromosome DSD (45, X/46,XY PGD or "mixed gonadal dysgenesis")
- One case (2.2\%) has Karyotyping (46, XY), female phenotype, diagnosed as complete Androgen insensitivity syndrome.

In Wong et al. ${ }^{\left({ }^{(8)}\right.}$ Study was limited by its retrospective nature, non-standardized DSD evaluation and the fact that just over a third of the patients had been evaluated for DSD.

While In the current study, its prospective study and all patients of proximal hypospadias had been evaluated for DSD. Y-chromosome gonadal dysgenesis can be complete or partial, and can be associated with $46, \mathrm{XY}$ or $45, \mathrm{X} / 46, \mathrm{XY}$ karyotype. Patients having complete gonadal dysgenesis (CGD) are phenotypically female with bilateral streak gonads. Patients with PGD have variable degree of but incomplete testicular development. The classical presentation of 45, X/46, XY PGD, also known as "mixed gonadal dysgenesis", features gonadal asymmetry with a descended dysgenetic testis and a streak gonad ${ }^{(8)}$.

In Wong et al. ${ }^{(8)}$ Study, only 3 of the 7 PGD patients in their study had gonadal asymmetry. Two $45, \mathrm{X} / 46, \mathrm{XY}$ and one 46,XY PGD patients in their study had bilateral descended testes, andanother 46,XY PGD patient had bilateral undescended testes in inguinal canals. Their finding ssuggest that symmetric testicular palpability or position does not preclude $45, \mathrm{X} / 46, \mathrm{XY}$ or $46, \mathrm{XYPGD}$.

In Our Study, one case of (45, X/46, XY PGD) presented with the classical presentation (gonadal asymmetry with a descended dysgenetic testis and a streak gonad).

Diagnosing Y-chromosome PGD has strong implication in gonadal management in view of thein creased risk of germ cell neoplasms, predominantly gonadoblastoma (GB) and bilateral intratubular germ cell neoplasia unclassified (ITGCNU) ${ }^{(9)}$.

We have previously reported that almost $40 \%$ of $45, \mathrm{X} / 46, \mathrm{XY}$ PGD children presenting with ambiguous genitalia or proximal hypospadias developed gonadal germ cell neoplasms ${ }^{(8)}$.

In Wong et al. ${ }^{(8)}$ study demonstrated that 3 out of 7(43\%) patients with Y-chromosome PGD had gonadal germ cell neoplasm detected at the age of 1 to 4 years. In 2 patients the tumor developed in the descended scrotal testes. Their findings suggest that boys presenting with proximal hypospadias and affected by PGD should have early removal of any non-functioning streak gonad and timely surveillance of the dysgenetic testes by biopsy regardless of the testicular positions.

In the current study, a case of Y chromosome PGD hadn't germ cell neoplasm at time of the study.

In the current study, all patients included were in the pediatric age group. Ages ranged from 6 months to 10 years. 
In Wong et al. ${ }^{(8)}$ study, studied 165 patients of proximal hypospadias with no reference to age group.

In the current study, 3 patients had positive family history of similar conditions and 5 Patients had history of positive consanguinity.

In Wong et al. ${ }^{(8)}$ work, the studied 165 patients had no reference or presence of family history or consanguinity.

In the current study, we used a combination of biochemical investigations, karyotyping, pelviabdominal US and or laparoscopy and histology of testis /gonads for diagnosis of DSD in proximal hypospadias. pelviabdominal us and Laparoscope show mullerian duct remnant in 4 cases. We had not use genetic analysis because it is not available.

In Wong et al. ${ }^{(8)}$ study, a combination of biochemical investigations, karyotyping, gene mutations and histology of testis/gonads was used to diagnose DSD. While No reference for presence or absence of mullerian duct remnant in this study.

\section{CONCLUSION}

- Patients presenting with proximal hypospadias and one or more of the co-existing anomalies of micro penis, undescended/impalpable testes, and penoscrotal transposition/bifid scrotum should warrant DSD evaluation.

- Presence of bilaterally descended testes in scrotum does not preclude the possibility of DSD.

- Presence of bilateral hernia of canal of nuck and palpable gonads in females should be investigated to exclude DSD.

\section{REFERENCES}

1. Snodgrass W, Macedo A, Hoebeke $P$ et al. (2011): Hypospadias dilemmas: a round table. J Pediatr Urol., $7(2): 145-57$.

2. Kearsey I, Hutson JM (2017): Disorders of sex development (DSD): not only babies with ambiguous genitalia. A practical guide for surgeons. Pediatr Surg Int., 33(3):355-361.

3. Nihoul-Fékété C (2003): The Isabel Forshall Lecture. Surgical management of the intersex patient: an overview in 2003. J Pediatr Surg.,39:144-5.

4. Lee PA, Houk CP, Ahmed SF et al. (2006): International Consensus Conference on Inter sex organized by the Lawson Wilkins Pediatric Endocrine Society and the European Society for Paediatric Endocrinology. Consensus statement on management of intersex disorders. International Consensus Conference on Intersex. Pediatrics, 118: 488-500.

5. Cox MJ, Coplen DE, Austin PF (2008): The incidence of disorders of sexual differentiation and chromosomal abnormalities of cryptorchidism and hypospadias stratified by meatal location. J Urol., 180:2649-52.

6. Hutson JM (2017): Cryptorchidism and Hypospadias. https://www.ncbi.nlm.nih. gov/books/NBK279106/

7. Ahmed SF, Achermann JC et al. (2011): UK guidance on the initial evaluation of an infant or an adolescent with a suspected disorder of sex development. Clinical Endocrinology, 75(1): 12-26.

8. Wong YS, Tam YH, Pang KKY et al. (2018): Incidence and diagnoses of disorders of sex development in proximal hypospadias. Journal of Pediatric Surgery, 53(12): 2498-2501.

9. McCann-Crosby B (2016): Ambiguous Genitalia: Evaluation and Management in the Newborn. Division of Pediatric Endocrinology Neo Reviews, 17(3): e144e53. 